\title{
Fast Reliable Algorithms for Matrices with Structure
}

by

T. Kailath, Ed.

Stanford University

A. H. Sayed, Ed.

University of California at Los Angeles

(C)1999 All rights reserved

342pp., published by SIAM, PA, 1999. 


\section{CONTENTS}

CONTRIBUTORS

xiv

SYMBOLS Xvi

PREFACE $\quad$ xviii

1 DISPLACEMENT STRUCTURE AND ARRAY ALGORITHMS 1

1.1 Introduction 2

1.2 Toeplitz Matrices 3

$\begin{array}{lll}1.3 & \text { Versions of Displacement Structure } & 7\end{array}$

1.4 Application to the Fast Evaluation of Matrix-Vector Products 15

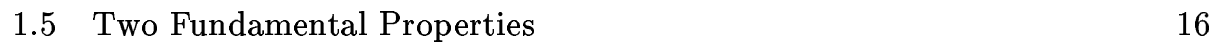

$\begin{array}{lll}1.6 & \text { Fast Factorization of Structured Matrices } & 18\end{array}$

$\begin{array}{lll}\text { 1.6.1 Schur Reduction (Deflation) } & 18\end{array}$

1.6.2 Close Relation to Gaussian Elimination 20

1.6.3 A Generalized Schur Algorithm 20

1.6.4 Array Derivation of the Algorithm 22

1.6.5 An Elementary Section 28

$\begin{array}{ll}\text { 1.6.6 A Simple Example } & 29\end{array}$

1.7 Proper Form of the Fast Algorithm 30

$\begin{array}{lll}\text { 1.7.1 Positive Steps } & 30\end{array}$

$\begin{array}{lll}\text { 1.7.2 Negative Steps } & 31\end{array}$

1.7.3 Statement of the Algorithm in Proper Form 32

1.7.4 A Transmission Line Cascade 32

1.7.5 Shift-Structured $(\mathrm{F}=\mathrm{Z})$ Positive-Definite Matrices 33

1.7.6 The Classical Schur Algorithm 34

1.7.7 The Special Case of Toeplitz Matrices 36 
1.8 Some Applications in Matrix Computation 36

1.8.1 Going Beyond $\mathrm{F}=\mathrm{Z} \quad 37$

1.8.2 Simultaneous Factorization of $\mathrm{T}$ and $\mathrm{T}^{-1} \quad 37$

1.8.3 QR Factorization of Structured Matrices 39

1.8.4 Avoiding Back-Substitution in Linear Equations 40

1.9 Look-Ahead (Block) Schur Algorithm 40

1.10 Fast Inversion of Structured Matrices 43

1.10.1 Schur Construction (Inflation) 44

1.10.2 Statement of the Fast Inversion Algorithm 46

1.10.3 Algorithm Development 47

1.10.4 An Example $\quad 49$

1.10.5 Proper Form of the Algorithm 50

1.10.6 Application to Pick Matrices $\quad 52$

1.10.7 The Degenerate Case 53

1.11 Non-Hermitian Toeplitz-like Matrices $\quad 54$

1.12 Schur Algorithm for Hankel-Like Matrices $\quad 55$

$\begin{array}{ll}1.13 \text { Structured Matrices and Pivoting } & 57\end{array}$

1.13.1 Incorporating Pivoting into Generalized Schur Algorithms $\quad 57$

1.13.2 Transformations to Cauchy-Like Structures $\quad 59$

$\begin{array}{ll}1.13 .3 \text { Numerical Issues } & 60\end{array}$

1.14 Some Further Issues $\quad 61$

1.14.1 Incorporating State-Space Structure $\quad 62$

1.14.2 Iterative Methods 63

1.14.3 Interpolation Problems 64

$\begin{array}{ll}1.14 .4 \text { Inverse Scattering } & 65\end{array}$

2 STABILIZED SCHUR ALGORITHMS

2.1 Introduction $\quad 69$

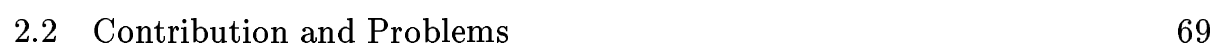

$\begin{array}{lll}2.3 & \text { Related Works in the Literature } & 70\end{array}$

$\begin{array}{lll}2.3 .1 & \text { Notation } & 72\end{array}$

2.3.2 Brief Review of Displacement Structure $\quad 72$

$\begin{array}{ll}2.4 \text { The Generalized Schur Algorithm } & 74\end{array}$

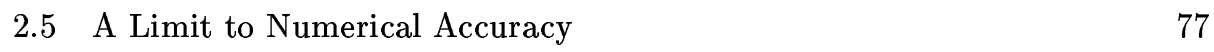

2.6 Implementations of the Hyperbolic Rotation $\quad 79$

$\begin{array}{lll}2.6 .1 & \text { Direct Implementation } & 79\end{array}$

$\begin{array}{lll}2.6 .2 & \text { Mixed Downdating } & 80\end{array}$ 
$\begin{array}{lll}2.6 .3 & \text { The OD Procedure } & 80\end{array}$

2.6.4 The H Procedure $\quad 82$

2.7 Implementation of the Blaschke Matrix $\quad 83$

2.7.1 The Case of Diagonal F $\quad 83$

2.7.2 The Case of Strictly-Lower Triangular F 84

2.8 Enforcing Positive-Definiteness $\quad 85$

2.9 Accuracy of the Factorization $\quad 85$

$\begin{array}{ll}2.10 \text { Pivoting with Diagonal F } & 87\end{array}$

$\begin{array}{ll}2.10 .1 \text { A Numerical Example } & 88\end{array}$

2.10.2 The Case of Positive F $\quad 88$

$\begin{array}{ll}2.10 .3 \text { The Non-Positive Case } & 89\end{array}$

2.11 Controlling the Generator Growth $\quad 89$

2.12 Solution of Linear Systems of Equations $\quad 90$

2.12.1 Computing the Matrix R 90

2.12.2 Iterative Refinement $\quad 91$

2.13 Enhancing the Robustness of the Algorithm 91

2.13.1 Enhancing the OD Method 92

2.13.2 Enhancing the H Procedure $\quad 93$

2.13.3 A Numerical Example $\quad 93$

2.14 Results for the Positive-Definite Case $\quad 94$

2.A Pseudo-Code for the Stable Schur Algorithm 96

3 FAST STABLE SOLVERS FOR STRUCTURED LINEAR SYSTEMS $\quad 100$

$\begin{array}{lll}3.1 & \text { Introduction } & 101\end{array}$

$\begin{array}{ll}3.2 & \text { Overview of the Proposed Solution } \\ 3.302\end{array}$

3.3 The Generalized Schur Algorithm for Indefinite Matrices 103

3.4 Fast QR Factorization of Shift-Structured Matrices 106

$\begin{array}{lll}3.4 .1 & \text { The Toeplitz Case } & 108\end{array}$

$\begin{array}{lll}3.4 .2 & \text { Other Augmentations } & 109\end{array}$

3.5 Well-Conditioned Coefficient Matrices 110

3.5.1 Implementation of the Hyperbolic Rotation 111

3.5.2 Avoiding Breakdown 113

3.5.3 Error Analysis of the Last Steps 114

$\begin{array}{lll}3.5 .4 & \text { Summary } & 114\end{array}$

3.5.5 Solving the Linear System of Equations 115

$\begin{array}{ll}3.6 & \text { Ill-Conditioned Coefficient Matrices } \\ 115\end{array}$

3.6.1 Solving the Linear System of Equations 116 
viii

3.6.2 Conditions on the Coefficient Matrix 117

$\begin{array}{lll}3.7 & \text { Summary of the Algorithm } & 117\end{array}$

4 STABILITY OF FAST ALGORITHMS FOR STRUCTURED LINEAR SYSTEMS $\quad 121$

4.1 Introduction $\quad 122$

$\begin{array}{lll}4.1 .1 & \text { Outline } & 123\end{array}$

4.1.2 Notation 124

$\begin{array}{lll}4.2 & \text { Stability and Weak Stability } & 124\end{array}$

4.2.1 Gaussian Elimination With Pivoting 125

4.2.2 Weak Stability 126

4.2.3 Example: Orthogonal Factorization $\quad 127$

$\begin{array}{lll}4.3 & \text { Classes of Structured Matrices } & 128\end{array}$

4.3.1 Cauchy and Cauchy-Like Matrices 128

$\begin{array}{ll}\text { 4.3.2 Toeplitz Matrices } & 129\end{array}$

4.4 Structured Gaussian Elimination $\quad 129$

$\begin{array}{ll}\text { 4.4.1 The GKO-Toeplitz Algorithm } & 130\end{array}$

4.4.2 Error Analysis 131

4.4.3 A General Strategy 132

4.5 Positive-Definite Structured Matrices 133

4.5.1 The Bareiss Algorithm for Positive-Definite Matrices 133

4.5.2 Generalized Schur Algorithms 134

$\begin{array}{lll}4.6 & \text { Fast Orthogonal Factorization } & 135\end{array}$

4.6.1 Use of the Semi-Normal Equations 135

4.6.2 Computing Q Stably 136

4.6.3 Solution of Indefinite or Unsymmetric Structured Systems 136

$\begin{array}{lll}4.7 & \text { Concluding Remarks } & 137\end{array}$

5 ITERATIVE METHODS FOR LINEAR SYSTEMS WITH MATRIX STRUCTURE $\quad 138$

$\begin{array}{lll}5.1 \text { Introduction } & 139\end{array}$

5.2 The Conjugate Gradient Method 139

$\begin{array}{lll}5.3 & \text { Iterative Methods for Solving Toeplitz Systems } & 143\end{array}$

$\begin{array}{lll}\text { 5.3.1 Preconditioning } & 145\end{array}$

$\begin{array}{lll}\text { 5.3.2 Circulant Matrices } & 146\end{array}$

$\begin{array}{lll}\text { 5.3.3 Toeplitz Matrix-Vector Multiplication } & 147\end{array}$

5.3.4 Circulant Preconditioners 148

5.4 Band-Toeplitz Preconditioners 154 
5.5 Toeplitz-Circulant Preconditioners $\quad 156$

$\begin{array}{lll}5.6 & \text { Preconditioners for Structured Linear Systems } & 158\end{array}$

$\begin{array}{lll}\text { 5.6.1 Toeplitz-Like Systems } & 158\end{array}$

5.6.2 Toeplitz-Plus-Hankel Systems 162

$\begin{array}{lll}5.7 & \text { Toeplitz-Plus-Band Systems } & 165\end{array}$

$\begin{array}{ll}5.8 \text { Applications } & 166\end{array}$

5.8.1 Linear-Phase Filtering 166

5.8.2 Numerical Solutions of Biharmonic Equations 168

5.8.3 Queueing Networks with Batch Arrivals 170

$\begin{array}{ll}\text { 5.8.4 Image Restorations } & 175\end{array}$

$\begin{array}{lll}5.9 \text { Concluding Remarks } & 177\end{array}$

$\begin{array}{lll}\text { 5.A Proof of Theorem 5.3.4 } & 178\end{array}$

5.B Proof of Theorem 5.6.2 180

6 ASYMPTOTIC SPECTRAL DISTRIBUTION OF TOEPLITZRELATED MATRICES

$\begin{array}{lll}6.1 \text { Introduction } & 183\end{array}$

$\begin{array}{ll}\text { 6.2 What is Spectral Distribution? } & 183\end{array}$

$\begin{array}{lll}\text { 6.3 Toeplitz Matrices and Shift-Invariance } & 187\end{array}$

$\begin{array}{lll}\text { 6.3.1 Spectral Distribution of Toeplitz Matrices } & 189\end{array}$

6.3.2 Unbounded Generating Function 193

6.3.3 Eigenvalues in the Non-Hermitian Case 194

6.3.4 The Szegő Formula for Singular Values 196

$\begin{array}{lll}6.4 & \text { Multilevel Toeplitz Matrices } & 198\end{array}$

6.5 Block Toeplitz Matrices 203

6.6 Combining Block and Multilevel Structure 207

$\begin{array}{lll}6.7 & \text { Locally Toeplitz Matrices } & 209\end{array}$

6.7.1 A Closer Look at Locally Toeplitz Matrices 212

6.7.2 Spectral Distribution of Locally Toeplitz Sequences 217

6.8 Concluding Remarks 222

7 NEWTON'S ITERATION FOR STRUCTURED MATRICES 225

$\begin{array}{lll}7.1 & \text { Introduction } & 226\end{array}$

7.2 Newton's Iteration for Matrix Inversion 227

7.3 Some Basic Results on Toeplitz-like Matrices 229

7.4 The Newton-Toeplitz Iteration 232

7.4.1 Bounding the Displacement Rank 232

7.4.2 Convergence Rate and Computational Complexity 234 
7.4.3 An Approach Using f-Circulant Matrices 236

$\begin{array}{lll}7.5 & \text { Residual Correction Method } & 239\end{array}$

7.5.1 Application to Matrix Inversion 239

7.5.2 Application to a Linear System of Equations 239

7.5.3 Application to a Toeplitz Linear System of Equations 240

7.5.4 Estimates for the Convergence Rate 242

$\begin{array}{lll}7.6 & \text { Numerical Experiments } & 244\end{array}$

7.7 Concluding Remarks $\quad 245$

$\begin{array}{lll}\text { 7.A Correctness of Algorithm 7.4.2 } & 248\end{array}$

$\begin{array}{ll}\text { 7.B Correctness of Algorithm 7.5.1 } & 249\end{array}$

7.C Correctness of Algorithm 7.5.2 250

8 FAST ALGORITHMS WITH APPLICATIONS TO MARKOV CHAINS AND QUEUEING MODELS 251

8.1 Introduction 252

8.2 Toeplitz Matrices and Markov Chains 253

8.2.1 Modeling of Switches and Network Traffic Control 255

8.2.2 Conditions for Positive Recurrence 256

8.2.3 Computation of the Probability Invariant Vector 257

8.3 Exploitation of Structure and Computational Tools 259

8.3.1 Block Toeplitz Matrices and Block Vector Product 260

8.3.2 Inversion of Block Triangular Block Toeplitz Matrices 264

8.3.3 Power Series Arithmetic 266

$\begin{array}{lll}8.4 \text { Displacement Structure } & 267\end{array}$

8.5 Fast Algorithms 269

8.5.1 The Fast Ramaswami Formula 270

$\begin{array}{ll}\text { 8.5.2 A Doubling Algorithm } & 271\end{array}$

8.5.3 Cyclic Reduction 274

8.5.4 Cyclic Reduction for Infinite Systems 278

8.5.5 Cyclic Reduction for Generalized Hessenberg Systems 285

$\begin{array}{lll}8.6 & \text { Numerical Experiments } & 287\end{array}$

9 TENSOR DISPLACEMENT STRUCTURES AND POLYSPECTRAL MATCHING 291

9.1 Introduction $\quad 292$

9.2 Motivation for Higher-Order Cumulants 292

9.3 Second-Order Displacement Structure 296

9.4 Tucker Product and Cumulant Tensors 299 
9.5 Examples of Cumulants and Tensors 302

9.6 Displacement Structure for Tensors 305

9.6.1 Relation to the Polyspectrum 307

$\begin{array}{ll}\text { 9.6.2 The Linear Case } & 310\end{array}$

$\begin{array}{lll}9.7 & \text { Polyspectral Interpolation } & 314\end{array}$

$\begin{array}{ll}9.8 \text { A Schur-Type Algorithm for Tensors } & 318\end{array}$

9.8.1 Review of Second-Order Case 318

9.8.2 A Tensor Outer Product 320

9.8.3 Displacement Generators 323

$\begin{array}{ll}9.9 \text { Concluding Remarks } & 327\end{array}$

10 MINIMAL COMPLEXITY REALIZATION OF STRUCTURED MATRICES $\quad 329$

10.1 Introduction $\quad 330$

10.2 Motivation of Minimal Complexity Representations 330

10.3 Displacement Structure $\quad 332$

10.4 Realization Theory for Matrices 333

10.4.1 Nerode Equivalence and Natural State Spaces 336

10.4.2 Algorithm for Finding a Realization 337

10.5 Realization of Low Displacement Rank Matrices 340

10.6 A Realization for the Cholesky Factor 343

$\begin{array}{ll}10.7 \text { Discussion } & 349\end{array}$

A USEFUL MATRIX RESULTS

A.1 Some Matrix Identities 353

A.2 The Gram-Schmidt Procedure and the QR Decomposition 359

$\begin{array}{ll}\text { A.3 Matrix Norms } & 360\end{array}$

A.4 Unitary and J-Unitary Transformations 361

A.5 Two Additional Results 363

B ELEMENTARY TRANSFORMATIONS $\mathbf{3 6 5}$

B.1 Elementary Householder Transformations 366

B.2 Elementary Circular or Givens Rotations $\quad 369$

B.3 Hyperbolic Transformations $\quad 371$

$\begin{array}{ll}\text { BIBLIOGRAPHY } & 381\end{array}$ 


\section{CONTRIBUTORS}

Dario A. BINI

Dipartimento di Matematica

Università di Pisa

Italy

Richard P. BRENT

Oxford University Computing Laboratory

Wolfson Bldg, Parks Road

Oxford OX1 3QD, England

Sheryl BRANHAM

Dept. Math. and Computer Science

City University of New York

Bronx, NY 10468, USA

Raymond H. CHAN

Department of Mathematics

The Chinese University of Hong Kong

Shatin, Hong Kong

Shivkumar CHANDRASEKARAN

Dept. Electrical and Computer Engineering

University of California

Santa Barbara, CA 93106, USA

Patrick DEWILDE

DIMES, POB 5031, 2600GA Delft

Delft University of Technology

Delft, The Netherlands

Victor S. GRIGORASCU

Facultatea de Electronica and Telecomunicatii

Universitatea Politehnica Bucuresti

Bucharest, Romania

Thomas KAILATH

Department of Electrical Engineering

Stanford University

Stanford, CA 94305, USA
Beatrice MEINI

Dipartimento di Matematica

Università di Pisa

Italy

Michael K. NG

Department of Mathematics

The University of Hong Kong

Pokfulam Road, Hong Kong

Victor Y. PAN

Dept. Math. and Computer Science

City University of New York

Bronx, NY 10468, USA

Phillip A. REGALIA

Signal and Image Processing Dept.

Inst. National des Télécommunications

F-91011 Evry cedex, France

Rhys E. RosholT

Dept. Math. and Computer Science

City University of New York

Bronx, NY 10468, USA

Ali H. SAYED

Electrical Engineering Department

University of California

Los Angeles, CA 90024, USA

Paolo TILLI

Scuola Normale Superiore

Piazza Cavalieri 7

56100 Pisa, Italy

Ailong ZhenG

Dept. Math. and Computer Science

City University of New York

Bronx, NY 10468, USA 